\title{
Perfil metabólico proteico de vacas em lactação alimentadas com milho e ureia a pasto
}

[Protein metabolic profile of dairy cows fed corn and urea pasture]

\author{
M.G. Guerra ${ }^{1}$, A.S.C. Veras $^{1}$, V.L.F. Santos ${ }^{2} *$, M.A. Ferreira ${ }^{1}$, L.P. Novaes ${ }^{3}$, L.M.G. Barreto ${ }^{4}$, \\ P.L.C.O. Câmara ${ }^{3}$, L.R. Silva ${ }^{4}$ \\ ${ }^{1}$ Universidade Federal Rural de Pernambuco - Recife, PE \\ ${ }^{2}$ Universidade Federal do Piauí - Bom Jesus, PI \\ ${ }^{3}$ Universidade Federal Rural do Semi-Árido \\ ${ }^{4}$ Universidade Federal de Sergipe - Nossa Senhora da Glória, SE
}

\begin{abstract}
RESUMO
Objetivou-se com este estudo avaliar os efeitos da substituição total do farelo de soja por milho e ureia sobre consumo e digestibilidade aparente da matéria seca, perfil metabólico proteico e balanço de nitrogênio de vacas mestiças em lactação em pastejo, com lotação intermitente de capim-mombaça (Panicum maximum). Foram utilizadas 12 vacas mestiças em lactação, com peso corporal médio inicial de 473,0+45,0kg, período de lactação médio de 95,0+42,2 dias e produção de leite de média inicial de $14,1 \pm 1,9 \mathrm{~kg} / \mathrm{dia}$. As vacas eram primíparas e multíparas, mestiças de Girolando, Pardo-Suíço e Jersey. Os tratamentos consistiram em quatro níveis de substituição do farelo de soja por milho e ureia $(0 ; 33 ; 66$; $100 \%$ na matéria seca - MS). O capim-mombaça apresentou teor médio de proteína bruta e fibra em detergente neutro de 19 e 59\% na MS, respectivamente. A substituição do farelo de soja por milho e ureia não alterou o consumo e a digestibilidade aparente da MS. As concentrações de ureia e N-ureico plasmáticos foram alteradas pela substituição do farelo de soja por milho e ureia. O balanço de nitrogênio foi positivo e não foi alterado com as substituições. Para vacas mestiças produzindo, em média, $12,5 \mathrm{~kg} / \mathrm{dia}$ e mantidas em pasto de qualidade, pode se substituir totalmente o farelo de soja por milho e ureia.
\end{abstract}

Palavras-chave: consumo, digestibilidade, N-ureico no plasma, proteína, suplementação

\begin{abstract}
The objective of this study was to evaluate the effects of total replacement of corn by soybean meal and urea on intake and apparent digestibility of dry matter, protein metabolic profile, and nitrogen balance of lactating crossbred cows grazing with intermittent stocking Mombasa grass (Panicum maximum). Twelve milking cows were distributed in a triple $4 \times 4$ latin design, with a mean initial body weight of $473,0 \pm 45,0 \mathrm{~kg}$, average lactation period of 95,0 $\pm 42,2$ days and milk production of initial mean of $14,1 \pm 1,9 \mathrm{~kg} /$ day. Cows were primiparous and multiparous. The treatments consisted of four levels of substitution of soybean meal for corn and urea $(0 ; 33 ; 66 ; 100 \%$ in dry matter - DM). The Mombasa grass showed an average content of crude protein and neutral detergent fiber of 19 and 59\% in DM, respectively. The concentrations of urea and plasma urea nitrogen were altered by replacing soybean meal with corn and urea. Protein metabolic profile was changed with the replacement of soybean meal by corn and urea. The nitrogen balance was positive and has not changed with the replacements. For mixedrace cows producing an average of $12.5 \mathrm{~kg} /$ day and kept in good-quality pastures, one can replace soybean meal totally with corn and urea.
\end{abstract}

Keywords: digestibility, intake, plasma urea nitrogen, protein, supplementation

Recebido em 8 de fevereiro de 2017

Aceito em 25 de agosto de 2017

* Autor para correspondência (corresponding author)

E-mail: vsantos1804@gmail.com 


\section{INTRODUÇÃO}

A produção animal em pastagens no Brasil é o sistema mais barato para se produzir carne ou leite a baixos custos, quando este é comparado ao sistema de confinamento à base de alimentos concentrados. Contudo, a maioria das áreas de pasto está degradada ou em processo de degradação, ou seja, o animal não tem à sua disposição alimento de qualidade e em quantidade suficiente para permitir o máximo desempenho.

Diversas pesquisas vêm sendo comumente realizadas com o objetivo de conhecer cada vez mais a forma como os ruminantes em produção expressam todo o seu potencial genético, em resposta à alimentação e ao ambiente em que são criados, sendo o pasto o principal alimento. No entanto, apenas com alimentação exclusiva de pastagens tropicais não tem sido possível alcançar médias e altas produções individuais de leite, sendo necessária a suplementação com concentrado para atingir esse potencial produtivo.

No Brasil, o farelo de soja é a principal fonte de proteína verdadeira utilizada para animais de produção, e a inclusão desse ingrediente pode resultar em maior custo dietético (Alves et al., 2010) em virtude da variação no preço conforme o mercado internacional.

O uso de ureia e de outros compostos nitrogenados não proteicos (NNP) em substituição a fontes proteicas na alimentação de ruminantes é comum, em razão do menor custo e dos benefícios que trazem aos animais quando utilizados de forma correta, devido à capacidade que os micro-organismos do rúmem têm em transformar o NNP em proteína de alto valor biológico (Gonçalves et al., 2014).

Estudos indicam que é possível a substituição do farelo de soja por outras fontes de NNP sem afetar o desempenho produtivo de vacas em lactação (Naves et al., 2015). No entanto, a literatura é restrita em relação ao uso de NNP quando vacas em lactação são mantidas em pastejo.

Assim, foi assumida a hipótese de que a substituição do farelo de soja por milho e ureia em dietas de vacas mestiças lactantes, mantidas em pastagens de capim-mombaça irrigadas e adubadas, pode ser recomendada sem que sejam alteradas a ingestão e a digestibilidade da matéria seca e o balanço de compostos nitrogenados.

Nesse contexto, objetivou-se, com este trabalho, avaliar o efeito da substituição do farelo de soja por milho e ureia em dietas para vacas leiteiras em pastejo intermitente de capim-mombaça, sobre o consumo e a digestibilidade da matéria seca, o perfil metabólico proteico e o balanço de nitrogênio de vacas mestiças.

\section{MATERIAL E MÉTODOS}

O manejo dos animais foi realizado de acordo com as recomendações do Conselho Nacional de Controle da Experimentação Animal - Concea (Brasil, 2008), com aprovação pela Comissão de Ética no Uso de Animais - Ceua - da Universidade Federal do Rio Grande do Norte UFRN, por meio do protocolo número 065/2014. O estudo foi conduzido no Setor de Bovinocultura Leiteira, pertencente à Universidade Federal do Rio Grande do Norte UFRN, na Unidade Acadêmica Especializada em Ciências Agrárias da Escola Agrícola de Jundiaí (EAJ), localizada no município de Macaíba, RN.

Os tratamentos experimentais consistiram na substituição do farelo de soja por milho e ureia $(0 ; 33 ; 66 ; 100 \%$ na MS). A dieta sem ureia foi formulada de acordo com o NRC (Nutrient..., 2001), para atender às exigências de vacas com $457 \mathrm{~kg}$ de peso corporal - PC - e produção média diária de $14 \mathrm{~kg}$ de leite, com 4,0\% de gordura (Tab. 1).

O experimento durou 68 dias, divididos em quatro períodos de 17 dias, dos quais 10 foram destinados à adaptação dos animais às dietas e os sete dias subsequentes, para coletas de dados e amostras. Os animais receberam a suplementação concentrada individualmente, durante as ordenhas matinal (seis horas) e vespertina (14h), em que foi fornecido $1 \mathrm{~kg}$ de concentrado (com base na MS) para cada $2 \mathrm{~kg}$ de leite produzidos acima de $8 \mathrm{~kg}$.

Imediatamente após a saída dos animais, os piquetes foram adubados com $400 \mathrm{~kg} / \mathrm{ha}$ de NPK $\left(\mathrm{N}, \mathrm{P}_{2} \mathrm{O}_{5}, \mathrm{~K}_{2} \mathrm{O}\right)$. A irrigação foi realizada das sete às 16 horas, em dias alternados. A análise de solo, a adubação e a irrigação foram realizadas de acordo com o manejo adotado no setor de bovinocultura da UFRN. 
Tabela 1. Proporção dos ingredientes e composição química das dietas experimentais

\begin{tabular}{ccccc}
\hline \multirow{2}{*}{ Ingredientes } & \multicolumn{4}{c}{ Níveis de substituição do farelo de soja por milho e ureia } \\
\cline { 2 - 5 } & 0 & 33 & 66 & 100 \\
\hline Milho moído & 620 & 675 & 729 & 784 \\
Farelo de soja & 194 & 129 & 65,0 & 0,00 \\
Farelo de trigo & 143 & 143 & 143 & 143 \\
Ureia/SA $^{1}$ (9:1) & 0,00 & 10,0 & 20,0 & 30,0 \\
Mistura mineral & 43,0 & 43,0 & 43,0 & 43,0 \\
\hline Itens & Composição química das dietas experimentais (g/kg MS) \\
\hline Matéria seca* & 860 & 850 & 841 & 832 \\
Matéria orgânica & 927 & 920 & 913 & 906 \\
Proteína bruta & 173 & 173 & 174 & 174 \\
Extrato etéreo & 32,9 & 34,0 & 35,1 & 36,2 \\
Fibra em detergente neutro & 164 & 163 & 161 & 160 \\
Fibra em detergente ácido & 48,6 & 41,7 & 34,9 & 28,0 \\
Carboidratos totais & 726 & 740 & 753 & 767 \\
Carboidratos não fibrosos & 456 & 469 & 482 & 496 \\
PIDN & 3,40 & 1,40 & 3,10 & 2,90 \\
PIDA & 0,20 & 0,20 & 0,10 & 0,10 \\
\hline
\end{tabular}

*g/kg na matéria natural; ${ }^{1} \mathrm{SA}=$ sulfato de amônia; PIDN=proteína insolúvel em detergente neutro; PIDA= proteína insolúvel em detergente ácido.

A fim de avaliar a qualidade do material fibroso ingerido pelo animal, foi realizado manualmente o pastejo simulado no primeiro e último dias de cada período de coleta, para obtenção de amostras compostas, por piquete e por período.

A ingestão da forragem foi estimada utilizandose o marcador externo dióxido de titânio (DT). Em cada período, durante 12 dias consecutivos, todos os animais receberam oralmente 15 gramas de DT, divididos em dois fornecimentos diários e ministrados por ingestão forçada. Nos últimos cinco dias de fornecimento do marcador, foram coletadas amostras individuais de fezes, diretamente do reto dos animais, duas vezes ao dia. As amostras de fezes foram congeladas a $20^{\circ} \mathrm{C}$ e, após o final do período de coletas, as amostras de cada animal foram descongeladas e reunidas para compor uma única amostra por animal. Em seguida, as amostras foram secas em estufa a $55-60^{\circ} \mathrm{C}$, por $120 \mathrm{~h}$, e moídas em peneira de $2 \mathrm{~mm}$. A análise da concentração fecal do DT foi efetuada conforme Detmann et al. (2012).

Os teores de MS, matéria mineral (MM), proteína bruta $(\mathrm{PB})$, extrato etéreo $(\mathrm{EE})$, fibra em detergente neutro (FDN) e fibra em detergente ácido (FDA), nitrogênio (N) insolúvel em detergente neutro (NIDN) e em detergente ácido (NIDA), nas amostras capim-mombaça, dos ingredientes das dietas experimentais e das fezes foram obtidos segundo Detmann et al. (2012).
A fibra em detergente neutro indigestível (FDNi) foi usada como indicador interno para estimar a produção de matéria seca fecal. Amostras de fezes e alimentos foram pré-secas a $55-60^{\circ} \mathrm{C}$, por 120 e $72 \mathrm{~h}$, respectivamente, moídas em peneiras de $2 \mathrm{~mm}$ e avaliadas quanto ao teor de FDNi, utilizando-se sacos de tecido não tecido (TNT, $100 \mathrm{~g} / \mathrm{m}^{2}$ ), incubados in situ, por um período de 288h, conforme Valente et al. (2011). Para tal, foi utilizado um bovino adulto, com PC de $600 \mathrm{~kg}$, alimentado com dieta constituída de $80 \%$ de silagem de capim-elefante e $20 \%$ de concentrado, após sete dias de adaptação.

No sexto dia de coleta de cada período experimental, foram coletadas amostras spot de urina de cada vaca, quatro horas após a refeição matinal, mediante micção estimulada por massagem na vulva. Após homogeneização e centrifugação das amostras de urina coletadas, retiraram-se duas alíquotas de $10 \mathrm{~mL}$. Uma alíquota foi diluída em $40 \mathrm{~mL}$ de ácido sulfúrico $(0,036 \mathrm{~N})$, para análise de ureia, e a outra amostra com a urina pura foi armazenada para a análise de creatinina, determinadas por meio de kits comerciais (Labtest $^{\circledR}$ ), seguindo as recomendações do fabricante em laboratório comercial.

O volume urinário médio diário foi estimado para cada animal, multiplicando-se o respectivo peso corporal pela excreção diária de creatinina 
$(\mathrm{mg} / \mathrm{kg}$ de peso corporal). Dividiu-se esse produto pela concentração de creatinina $(\mathrm{mg} / \mathrm{L})$ na urina spot, utilizando-se o valor $24,04 \mathrm{mg} / \mathrm{kg}$ de peso corporal de creatinina, encontrado por Chizzotti et al. (2008), para vacas Holandesas e mestiças, para o cálculo do balanço de nitrogênio.

O consumo total de nitrogênio foi determinado dividindo-se o valor da proteína bruta das amostras por 6,25 , obtendo-se a quantidade em gramas de nitrogênio consumido. $\mathrm{O}$ mesmo cálculo foi realizado com os valores de proteína bruta das fezes, obtendo-se a excreção total de nitrogênio, em g/kg de MS.

Para a determinação do nitrogênio total das amostras de urina e leite, foi utilizada a metodologia proposta por Detmann et al. (2012), em que a quantidade em gramas de nitrogênio para cada $100 \mathrm{~mL}$ de urina ou leite foi obtida dividindo-se o valor de proteína bruta das amostras pelo fator 6,25 para as amostras de urina, e do fator 6,38 para as amostras de leite.

O balanço de nitrogênio (BN) foi obtido pela diferença entre o total de nitrogênio ingerido $(\mathrm{N}$ total) e o total de $\mathrm{N}$ excretado nas fezes (Nfezes), na urina (N-urina) e no leite (N-leite).

A coleta de sangue dos animais foi efetuada em tubos a vácuo (Vacutainer ${ }^{\circledR}$ ), um com ativador de coágulo para obtenção de soro e outro com EDTA, antes do fornecimento do concentrado e da ordenha matinal e quatro horas após o fornecimento do concentrado, no último dia de cada período experimental, durante a pesagem dos animais, na veia jugular. Imediatamente, as amostras foram submetidas à centrifugação a 3.200 giros por 20 minutos, e foram retiradas quatro alíquotas de plasma sanguíneo.

No soro, foram determinados os valores de proteínas totais, globulinas, albuminas, hemoglobina e ureia, por meio de kits comerciais; no plasma, foi determinado o nitrogênio ureico no plasma (NUP), por meio do fator de correção 0,466, segundo Coelho da Silva e Leão (1979), que corresponde a 46,6\% do teor de nitrogênio da ureia. Todas as análises foram determinadas com o uso de kits da marca Labtest $^{\circledR}$, de espectofotômetro, em laboratório comercial.

As variáveis estudadas foram submetidas a análises de variância e regressão, utilizando-se o procedimento MIXED do SAS, versão 9.1, adotando-se o nível de $5 \%$ de probabilidade.

\section{RESULTADOS E DISCUSSÃO}

A composição bromatológica das amostras oriundas do pastejo simulado de capim-mombaça foi de $200 \mathrm{~g}$ de $\mathrm{MS} / \mathrm{kg}$ de matéria natural; $904 \mathrm{~g}$ de matéria orgânica; $190 \mathrm{~g}$ de proteína bruta; $595 \mathrm{~g}$ de fibra em detergente neutro e $94,3 \mathrm{~g}$ de carboidratos não fibrosos (Tab. 2).

Tabela 2. Composição química da forragem e ingredientes das dietas experimentais

\begin{tabular}{ccccc} 
& Capim-mombaça & Farelo de soja & Milho moído & Farelo de trigo \\
\hline MS & 200,7 & 897,2 & 904,2 & 900,8 \\
MO $^{1}$ & 904,1 & 938,0 & 982,4 & 955,9 \\
PB $^{1}$ & 190,7 & 463,3 & 85,10 & 183,6 \\
FDN $^{1}$ & 595,0 & 140,1 & 140,7 & 351,3 \\
CNF $^{1}$ & 94,30 & 276,1 & 568,0 & 355,5 \\
\hline
\end{tabular}

$* \mathrm{~g} / \mathrm{kg}$ na matéria natural.

${ }^{1} \mathrm{~g} / \mathrm{kg}$ na matéria seca

$\mathrm{MS}=$ matéria seca; $\mathrm{MO}=$ matéria orgânica; $\mathrm{PB}=$ proteína bruta; $\mathrm{FDN}=$ fibra em detergente neutro; $\mathrm{CNF}=$ carboidratos não fibrosos.

$\mathrm{O}$ alto teor de $\mathrm{PB}$ verificado no capim-mombaça foi consequência do manejo da pastagem associado à adubação nitrogenada e irrigação, bem como ao menor intervalo entre pastejo, de 15 dias, que favoreceu o aumento tanto na produção de matéria seca como no valor proteico da gramínea. As adubações, principalmente a nitrogenada, além de aumentarem a produção de matéria seca, aumentam o teor de proteína bruta da forragem e, em alguns casos, diminuem o teor de fibra e, com isso, contribuem para um melhor valor nutritivo (Alencar et al., 2014). 
Não houve efeito da substituição do farelo de soja pelo milho e ureia sobre o consumo de matéria seca do pasto $($ CMS pasto $=11,91 \mathrm{~kg} / \mathrm{dia})$ e matéria seca total $(\mathrm{CMS}$ total $=15,3 \mathrm{~kg} / \mathrm{dia}$ ou $3,3 \%$ do peso corporal) (Tab. 3). Esses valores são condizentes e justificáveis com os preconizados pelo NRC (Nutrient..., 2001), de $13,7 \mathrm{~kg} / \mathrm{dia}$ e $3,0 \%$ do peso corporal, para uma vaca leiteira pesando $457 \mathrm{~kg}$ de peso corporal, produzindo $12,5 \mathrm{~kg}$ de leite corrigido para $4,1 \%$ de gordura, o que pode ser explicado pelo fato de que alimentos que possuem alto valor nutritivo e alta digestibilidade elevam o CMS, ocasionado pela maior taxa de passagem no trato gastrointestinal.

O tempo de ruminação tende a ser menor com o consumo de fibra de melhor qualidade, relacionado à concentração de FDN e ao tamanho de partículas da fibra. Isso, consequentemente, aumenta o tempo disponível para alimentação. A forragem fornecida neste trabalho apresentou características desejáveis que podem ter provocado esse aumento no CMS pela adequada concentração de FDN (\%), resultante da idade precoce do capim colhido pelos animais.

Tabela 3. Consumo e digestibilidade da matéria seca de vacas em lactação alimentadas com dietas contendo diferentes níveis de substituição do farelo de soja por milho e ureia

\begin{tabular}{|c|c|c|c|c|c|c|c|}
\hline \multirow[t]{2}{*}{ Variável } & \multicolumn{4}{|c|}{$\begin{array}{c}\text { Níveis de substituição do farelo } \\
\text { de soja por milho e ureia }\end{array}$} & \multirow[t]{2}{*}{$\mathrm{EPM}^{1}$} & \multicolumn{2}{|c|}{ Efeito } \\
\hline & 0 & 33 & 66 & 100 & & Linear & Quadrático \\
\hline CMS pasto, $\mathrm{kg} / \mathrm{dia}$ & 11,9 & 12,0 & 11,8 & 11,9 & 0,740 & 0,9160 & 0,9478 \\
\hline CMS total, $\mathrm{kg} / \mathrm{dia}^{2}$ & 15,2 & 15,4 & 15,1 & 15,2 & 0,716 & 0,9157 & 0,9485 \\
\hline CMS total, \%PC & 3,33 & 3,39 & 3,29 & 3,30 & 0,252 & 0,7577 & 0,8302 \\
\hline CFDN, $\mathrm{kg} / \mathrm{dia}^{3}$ & 8,00 & 8,00 & 8,00 & 8,00 & 0,41 & 0,89 & 0,94 \\
\hline $\mathrm{CPB}, \mathrm{kg} / \mathrm{dia}$ & 3,00 & 3,00 & 3,00 & 3,00 & 0,13 & 0,85 & 0,97 \\
\hline CNDT, kg/dia & 9,52 & 9,61 & 9,27 & 9,77 & 0,590 & 0,8195 & 0,6016 \\
\hline $\mathrm{DMS}^{4},(\%)$ & 72,8 & 72,6 & 72,0 & 72,7 & 1,11 & 0,7385 & 0,4995 \\
\hline $\mathrm{PL}^{5}, \mathrm{~kg} / \mathrm{dia}$ & 12,5 & 12,3 & 12,0 & 12,0 & 0,589 & 0,2840 & 0,8901 \\
\hline
\end{tabular}

${ }^{1} \mathrm{EPM}=$ erro-padrão da média; ${ }^{2} \mathrm{CMS}$ total (pasto + suplemento) $;{ }^{3} \mathrm{CFDN}=$ consumo de fibra em detergente neutro; ${ }^{4} \mathrm{DMS}=$ digestibilidade da matéria seca $(\mathrm{CMS}) ;{ }^{5} \mathrm{PL}=$ produção de leite corrigido para $4 \%$ de gordura

Quanto maior o teor de fibra do alimento, mais lenta é a digestão e a retenção dele ocupando espaço no rúmen (Mertens, 2009). O aumento do CMS pelos animais em relação ao preconizado pelo NRC (Nutrient..., 2001) é justificável nesse estágio de lactação para que recuperem suas reservas corporais perdidas no início da lactação, fato ocasionado pela limitação de CMS adequada para manutenção da produção.

De acordo com o NRC (2001), as exigências de NDT e PB para mantença e produção de vacas em condições de pastejo, com produção de $12,5 \mathrm{~kg}$ de leite com $4,1 \%$ de gordura, peso corporal de $457 \mathrm{~kg}$ e com ganho médio de peso de $0,300 \mathrm{~kg} / \mathrm{animal} / \mathrm{dia}$, são de $9,1 \mathrm{~kg} / \mathrm{dia}$ e $1,9 \mathrm{~kg} / \mathrm{dia}$, respectivamente. Neste estudo, o consumo de NDT foi semelhante ao preconizado pelo NRC (Nutrint..., 2001), mas o consumo de
PB foi superior à exigência para todos os níveis de substituição de soja por milho e ureia.

Ao se fazer uma simulação de quanto apenas a forragem consumida, sem a inclusão do concentrado, fornece de MS, NDT e PB para esses animais, pôde-se perceber que houve um déficit de $1,8 \mathrm{~kg}$ e $2,0 \mathrm{~kg}$ de $\mathrm{MS}$ e NDT, respectivamente, e um excedente de $0,340 \mathrm{~kg}$ de PB. Esse resultado mostra que, nessas condições, apenas a suplementação energética seria suficiente para que os animais atingissem a produção em questão. Outro fator relacionado à falta de energia da forragem seria as condições em que esta se apresenta no período de crescimento, com baixos teores de carboidratos não fibrosos, sendo os carboidratos disponíveis de degradação mais lenta e a proteína da forragem altamente degradável, o que provoca desbalanço entre energia e proteína e, 
consequentemente, ocasiona limitações no desempenho animal (Santos et al., 2007), resultado que reitera a indicação da suplementação energética.

O coeficiente de digestibilidade aparente da MS não foi alterado com a substituição do farelo de soja por milho e ureia nos concentrados (Tab. 3). Isso sugere que a inclusão de milho e ureia nos concentrados em substituição ao farelo de soja manteve o equilíbrio da microbiota ruminal e, como consequência, a alta digestibilidade, em razão das características dos alimentos fornecidos, além da maior participação de fibras de boa qualidade por meio do volumoso, que contribui para a manutenção das condições ótimas do rúmen, favorecendo a salivação e a manutenção do $\mathrm{pH}$ adequado para a atividade microbiana (Mertens, 1992). As produções médias de leite para cada tratamento estão apresentadas na Tab. 3. A produção de leite média dos animais foi de $12,23 \mathrm{~kg} /$ dia durante todo o período experimental.

As concentrações de creatinina e ureia na urina, creatinina no sangue, albumina, proteínas totais, globulinas e hemoglobinas, antes e após o fornecimento dos concentrados, não foram influenciadas pelos níveis de substituição do farelo de soja por milho e ureia (Tab. 4).

Tabela 4. Metabólitos urinários e sanguíneos de vacas em lactação, antes e após quatro horas do fornecimento do concentrado, com diferentes níveis de substituição do farelo de soja por milho e ureia

\begin{tabular}{|c|c|c|c|c|c|c|c|}
\hline \multirow[t]{2}{*}{ Variável } & \multicolumn{4}{|c|}{$\begin{array}{l}\text { Níveis de substituição do farelo de soja por } \\
\text { milho e ureia }\end{array}$} & \multirow[t]{2}{*}{$\mathrm{EPM}^{1}$} & \multicolumn{2}{|c|}{ Efeito } \\
\hline & 0 & 33 & 66 & 100 & & Linear & Quadrático \\
\hline \multicolumn{8}{|c|}{ Urina } \\
\hline Creatinina, $\mathrm{mg} / \mathrm{dL}$ & 53,96 & 51,88 & 56,88 & 55,63 & 9,351 & 0,5398 & 0,9076 \\
\hline Ureia, mg/dL & 1429 & 1293 & 1384 & 1283 & 154,70 & 0,4428 & 0,8615 \\
\hline \multicolumn{8}{|c|}{ Parâmetros sanguíneos antes do fornecimento do concentrado } \\
\hline Ureia, mg/dL & 39,67 & 37,75 & 34,25 & 36,08 & 3,720 & $0,0368^{2}$ & 0,0832 \\
\hline $\mathrm{NUP}^{3}, \mathrm{mg} / \mathrm{dL}$ & 18,48 & 17,59 & 15,96 & 16,81 & 0,594 & $0,0350^{4}$ & 0,1670 \\
\hline Creatinina, $\mathrm{mg} / \mathrm{dL}$ & 1,03 & 1,00 & 0,99 & 1,01 & 0,070 & 0,4575 & 0,3278 \\
\hline Albumina, g/dL & 2,77 & 2,74 & 2,63 & 2,76 & 0,097 & 0,6504 & 0,2311 \\
\hline Proteínas totais, g/dL & 8,70 & 8,43 & 8,14 & 8,51 & 0,268 & 0,1977 & 0,0545 \\
\hline Globulinas, g/dL & 5,93 & 5,69 & 5,51 & 5,74 & 0,266 & 0,2775 & 0,1373 \\
\hline Hemoglobina, g/dL & 9,68 & 9,47 & 9,55 & 9,50 & 0,394 & 0,3048 & 0,387 \\
\hline \multicolumn{8}{|c|}{ Parâmetros sanguíneos após o fornecimento do concentrado } \\
\hline Ureia, mg/dL & 41,25 & 40,33 & 40,08 & 40,42 & 3,469 & 0,5391 & 0,5327 \\
\hline NUP, mg/dL & 19,22 & 18,80 & 18,68 & 18,83 & 0,456 & 0,4746 & 0,6284 \\
\hline Creatinina, $\mathrm{mg} / \mathrm{dL}$ & 1,10 & 1,07 & 1,08 & 1,09 & 0,074 & 0,8358 & 0,1966 \\
\hline Albumina, $\mathrm{g} / \mathrm{dL}$ & 2,69 & 2,65 & 2,64 & 2,68 & 0,087 & 0,8897 & 0,4566 \\
\hline Proteínas totais, $\mathrm{g} / \mathrm{dL}$ & 8,55 & 8,53 & 8,59 & 8,59 & 0,309 & 0,7113 & 0,8903 \\
\hline Globulinas, g/dL & 5,78 & 5,84 & 5,92 & 5,87 & 0,308 & 0,7794 & 0,8173 \\
\hline Hemoglobina, g/dL & 9,06 & 9,20 & 9,31 & 9,26 & 0,318 & 0,9161 & 0,8188 \\
\hline
\end{tabular}

${ }^{1} \mathrm{EPM}=$ erro-padrão da média; ${ }^{2} \hat{\mathrm{Y}}=-0,0426 \mathrm{x}+39,055 ;{ }^{3}$ nitrogênio ureico no plasma $={ }^{4} \mathrm{Y}=-0,0198 \mathrm{x}+18,2$.

Houve influência $(\mathrm{P}<0,05)$ dos níveis de milho e ureia sobre a concentração de ureia no sangue quando os animais não haviam recebido a alimentação concentrada no período matinal, ocasionado, provavelmente, pelo menor aporte energético da alimentação proveniente do volumoso. Infere-se, portanto, que a alimentação proveniente do concentrado melhorou a relação energia:proteína e não provocou alterações na ureia sanguínea após o fornecimento dos concentrados (Tab. 4). Em que pese ter havido influência das dietas, o valor médio obtido na variável ureia no sangue está dentro dos valores de referência preconizados por González e Silva (2006), de $17-45 \mathrm{mg} / \mathrm{dL}$, o que pode ter sido ocasionado pela inclusão dos níveis de ureia nos concentrados. Segundo Garcia-Bojalil et al. (1998), o excesso de PB/PDR relacionado à falta de carboidratos fermentáveis ou o desbalanceamento entre a degradação de proteínas e a falta de energia aumentam as 
concentrações de ureia no sangue e/ou a excreção de ureia no leite e na urina.

Assim como foi observado com a ureia sanguínea, a substituição do farelo de soja por milho e ureia influenciou $(\mathrm{P}<0,05)$, de forma linear decrescente, as concentrações de NUP antes do fornecimento dos concentrados, cujos valores médios foram de $17,2 \mathrm{mg} / \mathrm{dL}$. Esses valores estão dentro da faixa de normalidade citada por Contreras (2000), de $2,6 \mathrm{mmol} / \mathrm{L}$ a $7 \mathrm{mmol} / \mathrm{L}$ de ureia no plasma, que correspondem a $7,28 \mathrm{mg} / \mathrm{dL}$ a $19,59 \mathrm{mg} / \mathrm{dL}$ de nitrogênio ureico no plasma. De acordo com Roseler et al. (1993), altas concentrações de NUP estão relacionadas a dietas com alto nível de PDR, associadas à falta de disponibilidade de material fermentescível no ambiente ruminal, e reiteram as observações encontradas neste estudo. Contudo, o excesso de PNDR, assim como de PDR, pode resultar na mesma condição, pois o excedente de nitrogênio, de origem ruminal ou pós-ruminal, é eliminado do organismo pelo mesmo processo de síntese hepática de ureia (Roseler et al., 1993).

Os valores médios de albumina e hemoglobinas estão abaixo dos valores de referência citados por González e Silva (2006), de 2,7-4,1g/dL e 9,8-13,0g/dL, respectivamente.

O efeito da maior ingestão de proteínas sobre o aumento nas concentrações desses componentes sanguíneos observados neste estudo é contraditório. No entanto, a energia fornecida nas dietas também pode ter efeito sobre os indicadores do metabolismo proteico e tem sido motivo de estudo.
Os valores médios de proteínas totais estão acima dos limites de referência, de $6,6-7,5 \mathrm{~g} / \mathrm{dL}$ (Tab. 4), o que é aceitável, já que estão relacionados com o estado nutricional do animal. A redução de proteínas totais está ligada a diversos fatores, entre eles a deficiência na nutrição. Já os valores de globulina estão acima do limite máximo de referência, de $3,0-5,2 \mathrm{~g} / \mathrm{dL}$ (González e Silva, 2006).

A substituição do farelo de soja por milho e ureia não influenciou na perda de nitrogênio fecal, urinário e no leite, sendo, portanto, as dietas uniformes (Tab. 5). O balanço de nitrogênio, expresso em g/dia, também não foi afetado e indica que houve retenção de proteína no organismo animal mediante o balanço positivo, com perdas médias de $52 \%$ do nitrogênio ingerido nas fezes, urina e leite. Isso significa que, aproximadamente, $48 \%$ do nitrogênio ingerido ficaram retidos no organismo das vacas.

A eficiência de utilização do nitrogênio (EUN) média foi de $13,3 \%$, indicando que foi muito baixa e que existe alta excreção de nitrogênio para o ambiente (Tab. 5). O valor de referência que determina ótima EUN está em torno de 30$35 \%$. Quanto maiores os níveis de proteína bruta na dieta, menor a EUN (Chase, 2003), sendo diretamente proporcional à produção de leite e inversamente proporcional ao teor de proteína na dieta. Portanto, quando há maior produção de leite com menor fornecimento de nitrogênio dietético, a EUN é mais alta (Jerszurki e Almeida, 2011).

Tabela 5. Balanço de nitrogênio e eficiência de utilização do nitrogênio (EUN) de vacas em lactação, alimentadas com milho e ureia em substituição ao farelo de soja

\begin{tabular}{ccccccccc}
\hline \multirow{2}{*}{ Variável } & \multicolumn{3}{c}{ Níveis de substituição do farelo de soja por } & & \multicolumn{2}{c}{ Efeito } \\
\cline { 2 - 4 } & 0 & 33 & 66 & 100 & & Linear & Quadrático \\
\hline N ingerido (g/dia) & 460 & 462 & 454 & 458 & 9,256 & 0,4210 & 0,4923 \\
N fecal (g/dia) & 107 & 106 & 108 & 106 & 2,668 & 0,5171 & 0,5520 \\
N urina (g/dia) & 67,7 & 74,0 & 62,9 & 70,0 & 2,892 & 0,8400 & 0,8376 \\
N leite (g/dia) & 61,2 & 60,8 & 59,3 & 58,5 & 1,545 & 0,1087 & 0,3099 \\
Balanço N (g/dia) & 224 & 221 & 223 & 223 & 8,923 & 0,4722 & 0,6182 \\
EUN ${ }^{2}$ (\%) & 13,4 & 13,3 & 13,1 & 13,3 & 0,437 & 0,6012 & 0,7418 \\
\hline
\end{tabular}

${ }^{1} \mathrm{EPM}=$ erro-padrão da média; ${ }^{2} \mathrm{EUN}$ : (N leite/N ingerido) $\mathrm{x} 100$. 


\section{CONCLUSÃo}

A substituição total do farelo de soja por milho e ureia para vacas mestiças, no terço médio de lactação, as quais produziam, em média, $12,5 \mathrm{~kg} /$ dia, e eram mantidas em pastagens de capim-mombaça irrigadas e adubadas, pode ser recomendada, visto que não altera o consumo e a digestibilidade da matéria seca, bem como o balanço de nitrogênio de vacas mestiças.

\section{REFERÊNCIAS}

ALENCAR, C.A.B.; MARTINS, C.E.; OLIVEIRA, R.A. et al. Bromatologia e digestibilidade de gramíneas manejadas por corte submetidas à adubações nitrogenadas e estações anuais. Biosci. J., v.30, p.8-15, 2014.

ALVES, A.F.; ZERVOUDAKIS, J.T.; ZERVOUDAKIS, L.K.H. et al. Substituição do farelo de soja por farelo de algodão de alta energia em dietas para vacas leiteiras em produção: consumo, digestibilidade dos nutrientes, balanço de nitrogênio e produção leiteira. Rev. Bras. Zootec., v.39, p.532-540, 2010.

BRASIL. Conselho Nacional de Controle da Experimentação Animal (CONCEA). Lei $\mathrm{n}^{\circ}$ $11.794 / 2008$. Regulamenta o inciso VII do $\S 1^{\circ}$ do art. 225 da Constituição Federal, estabelecendo procedimentos para o uso científico de animais. Disponível em: <http://www.planalto.gov.br/ccivil_03/_ato20072010/2008/lei/111794.htm>. Acessado em 01 dez. 2015.

CHASE, L.E. Nitrogen utiilization in dairy cows - what are the limits of efficiency? [s.1.]: Department of Animal Science. Cornell University, 2003. 12p

CHIZZOTTI, M.L.; VALADARES FILHO, S.C.; VALADARES, R.F.D. et al. Determination of creatinine excretion and evaluation of spot urine sampling in Holstein cattle. Livest. Sci., v.113, p.218-225, 2008.

CONTRERAS, P.A. Indicadores do metabolismo proteico utilizados nos perfis metabólicos de rebanhos. In: GONZÁLEZ, F.H.D. et al. (Ed.). Perfil metabólico em ruminantes: seu uso em nutrição e doenças nutricionais. Porto Alegre: UFRGS, 2000. p.23-30.
DETMANN, E.; SOUZA, M.D.; VALADARES FILHO, S.C. et al. Métodos para análise de alimentos - INCT - Ciência Animal. Visconde do Rio Branco: Suprema, 2012. 214p.

GARCIA-BOJALIL， C.M.; STAPLES, C.R., RISCO, C.A. et al. Protein degradability and calcium salts of long-chain fatty acids in the diets of lactating dairy cows: reproductive responses. J. Dairy Sci., v.81, p.1385-1395, 1998.

GONÇALVES, G.S.; PEDREIRA, M.S.; AZEVEDO, J.A.G. et al. Replacement of soybean meal by conventional and coated urea in dairy cows: intake, digestibility, production and composition of milk. Acta Sci. Anim. Sci., v.36, p.71-78, 2014.

GONZÁLEZ, F.H.D.; SILVA, S.C. Introdução à bioquímica clínica veterinária. Porto Alegre: Gráfica da Universidade Federal do Rio Grande do Sul, 2006. 357p.

JERSZURKI, D.; ALMEIDA, R. Adequação da nutrição proteica visando a excreção mínima de resíduos no meio ambiente. In: SANTOS, G.T.; KAZAMA, D.C.S.; DAMASCENO, J.C. et al. (Orgs.). SUL LEITE, 4. / SIMPÓSIO SOBRE SUSTENTABILIDADE DA PECUÁRIA LEITEIRA NA REGIÃO SUL DO BRASIL, 2011, Maringá. Anais... Maringá: Sthampa, 2011. v.1, p.9-25.

MERTENS, D.R. Análise da fibra e sua utilização na avaliação de alimentos e formulação de rações. In: SIMPÓSIO INTERNACIONAL DE RUMINANTES, 1992, Lavras. Anais... Lavras: Sociedade Brasileira de Zootecnia,1992. p.188-211.

MERTENS, D.R. Impact of NDF content and digestibility on dairy cow performance. WCDS Adv. Dairy Technol., v.21, p.191-201, 2009.

NAVES, J.R.; JESUS, E.F.; BARREIRO, J.R. et al. Substituição parcial do farelo de soja por diferentes fontes nitrogenadas em dietas a base de cana de açúcar na alimentação de vacas leiteiras. Vet. Zootec., v.22, p.101-113, 2015.

NUTRIENT requirements of dairy cattle. 7.ed. rev. Washington: National. Acadeny. Press, 2001. 381p. 


\section{Guerra et al.}

ROSELER, D.K.; FERGUSON, J.D.; SNIFFEN, C.J. HERREMA, J. Dietary protein degradability effects on plasma and milk urea nitrogen and milk nonprotein nitrogen in Holstein cows. $J$. Dairy Sci., v.76, p.525-534, 1993.

SANTOS, F.A.P.; CORREIA, P.S.; COSA, D.F.A. Sistemas intensivos de recria de bovinos com suplementação em pastagens e terminação em confinamento. In: SIMPÓSIO SOBRE BOVINOCULTURA DE CORTE, 6., 2007, Piracicaba. Anais... Piracicaba: FEALQ, 2007. p.163-181.
SILVA, J.F.C.; LEÃO, M.I. Fundamentos de nutrição de ruminantes. Piracicaba: Livroceres, 1979.

STATISTICAL analysis system. Version 8.2. Cary: SAS Institute, 2001.

VALENTE, T.N.P.; DETMANN, E.; VALADARES FILHO, S.C. et al. In situ estimation of indigestible compounds contents in cattle feed and feces using bags made from different textiles. Rev. Bras. Zootec., v.40, p.666675, 2011. 